\title{
AVALIAÇÃO DO ENSINO SUPERIOR: ANÁLISE DOS CURSOS AVALIADOS EM 2019 NA UNIVERSIDADE ESTADUAL DA PARAÍBA
}

http://dx.doi.org/10.5902/2318133855373

\author{
Bruno Henrique Oliveira Timbó ${ }^{1}$ \\ Maria das Graças Gonçalves Vieira Guerra²
}

\begin{abstract}
Resumo
Por meio deste texto apresenta-se resultados de pesquisa que teve como objetivo analisar o processo de avaliação dos cursos de graduação presencial na Universidade Estadual da Paraíba UEPB. Foram analisados os relatórios elaborados pelas comissões de verificação in loco designadas por intermédio do Conselho Estadual de Educação da Paraíba - CEE/PB. A análise Swot foi adotada como recurso para contribuir na identificação das forças, fraquezas, oportunidades e ameaças que impactaram de forma positiva e negativa na qualidade do processo avaliativo dos cursos de graduação presencial da UEPB. Nessa perspectiva, foi demonstrado um bom desempenho dos cursos avaliados nas dimensões de organização didático pedagógica e corpo docente e tutorial. Entretanto, a dimensão de infraestrutura mostrou-se ser uma fraqueza apresentada pelos cursos e pela UEPB em termos gerais. Constatou-se, ainda, que em relação aos cursos de graduação presencial, embora tenham tido uma avaliação favorável por parte das comissões de verificação in loco, faz-se necessário criar mecanismos permanentes de autoavaliação e de atualização dos projetos pedagógicos de cursos.

Palavras-chave: educação superior; avaliação do ensino superior; avaliação de cursos; UEPB.
\end{abstract}

\section{HIGHER EDUCATION EVALUATION: ANALYSIS OF COURSES EVALUATED IN 2019 AT THE STATE UNIVERSITY OF PARAÍBA}

\begin{abstract}
The present research had as general objective to analyze the evaluation process of the face-toface undergraduate courses at the State University of Paraíba - UEPB -, through the reports elaborated by the on-site verification commissions designated through the State Education Council of Paraíba - CEE/PB. We adopted the Swot analysis as a resource to contribute to the identification of the strengths, weaknesses, opportunities and threats that had a positive and negative impact on the quality of the evaluation process of the on-campus undergraduate courses of the researched $\mathrm{HEI}$. In this perspective, it was demonstrated a good performance of the courses evaluated in the dimensions of pedagogical didactic organization and faculty and tutorial. However, the infrastructure dimension proved to be a weakness presented by the courses and by the UEPB. It was found that, in relation to face-to-face undergraduate courses, although they had a favorable assessment by the on-site verification commissions, it is necessary to create permanent mechanisms for self-assessment and updating of the pedagogical course projects.

Key-words: college education; higher education evaluation; course evaluation; UEPB.
\end{abstract}

\footnotetext{
1 Universidade Estadual da Paraíba, Brasil. E-mail: brunohenrique083@hotmail.com.

2 Universidade Federal da Paraíba, Brasil. E-mail: gracinhavieira@yahoo.com.br. 


\section{Introdução}

$\mathrm{N}$ as últimas décadas a temática da avaliação da educação superior tem ganhado um lugar de destaque. "A avaliação do ensino superior encontra-se atrelada à noção de qualidade. Esta, por sua vez, pode incorporar uma polissemia de definições" (Souza; Guerra, 2020, p. 407). A qualidade, como conceito abstrato, implica algo que atenda a certas características que satisfaçam o que é desejado. No entanto, o que é considerado um serviço fornecido com qualidade depende da apreciação pessoal e de verificar-se a que ele serve, ou seja, é um julgamento subjetivo difícil de generalizar por meio de uma definição. Apesar deste conceito ser relativo, ele está de um modo geral dependente de quem julga.

De acordo com Haas (2017) a qualidade da educação é

um valor construído a partir das políticas e práticas que a regulamentam, tornando essa política um espaço de luta entre os diferentes interesses dos grupos que atuam na educação superior. Valores esses muitas vezes conflitantes e sem possibilidade de consenso, pois no espaço da educação superior habitam instituições públicas e privadas, e mesmo entre estas últimas há diferenças significativas dado que elas podem ser com ou sem fins lucrativos, comunitárias ou confessionais, e entre as públicas temos federais, estaduais ou municipais. (p. 120)

Apesar deste conceito estar dependente de quem julga, o conceito de qualidade refere-se à "tomada de decisões referente ao valor de algo serve como o ponto de interseção entre avaliação - que fornece as informações necessárias - e regulação governamental, que busca assegurar a oferta de bens e serviços de qualidade aos membros da sociedade (Verhine, 2015, p. 605)

Reconhece-se que a busca pela qualidade do ensino superior pressupõe a realização de processos avaliativos que tendem a explicitar nas IES os aspectos a serem melhorados. Guerra; Ribeiro (2019) ressaltam a importância do processo avaliativo das IES em que, "a partir dos resultados obtidos se torna possível delinear quais os rumos a serem tomados e quais os aspectos positivos e negativos que foram identificados" (p. 3).

É nesse contexto que surge a denominação de Estado-avaliador, posto que o Brasil adotou instrumentos de acompanhamento do desempenho das IES, cursos e alunos, desde 2004, pelo Sistema Nacional de Avaliação da Educação Superior - Sinaes - com "a finalidade de reorientar políticas públicas" (Freitas et al, 2011, p. 47).

Por causa do aumento no número de IES, da quantidade de oferta de vagas oferecidas e da expansão como um todo do sistema educacional brasileiro, compreendese que o Estado tenha passado a regular e avaliar a qualidade do ensino oferecido por tais instituições, a fim de garantir a sua finalidade social. O Estado, ao adotar a vertente de avaliador, ratifica a importância da avaliação justamente nessa monitorização de resultados, ponderando se os cursos oferecidos estão a funcionar com padrões de qualidade, norteando assim os rumos a serem tomados quando são identificadas falhas e fragilidades. 


\section{Avaliação do ensino superior}

Avaliação, segundo Vieira e Nogueira (2019), pode ser compreendida como a coleta de informações sobre um determinado processo, com o objetivo de aperfeiçoá-lo. Para Cavalcanti e Guerra (2019)

a avaliação não é somente um processo de conhecimento e juízo de valor suficiente ou encerrado em si mesmo. É também, e nisso consiste sua força política, um processo de intervenção direta sobre as decisões, tanto nos níveis mais restritos e internos quanto em termos de políticas públicas e de sistema. (p. 706)

Segundo Nunes; Duarte; Pereira (2017), a avaliação é uma ferramenta fundamental que viabiliza a identificação dos erros e equívocos cometidos para que a partir dessa informação se torne possível vencer os obstáculos e viabilizar a melhoria da instituição, dos seus cursos e da comunidade acadêmica como um todo. A ação avaliativa é um movimento que não deve ser considerado neutro, visto que ela causa transformações. Como destaca Dias Sobrinho (2008) a avaliação gera implicações

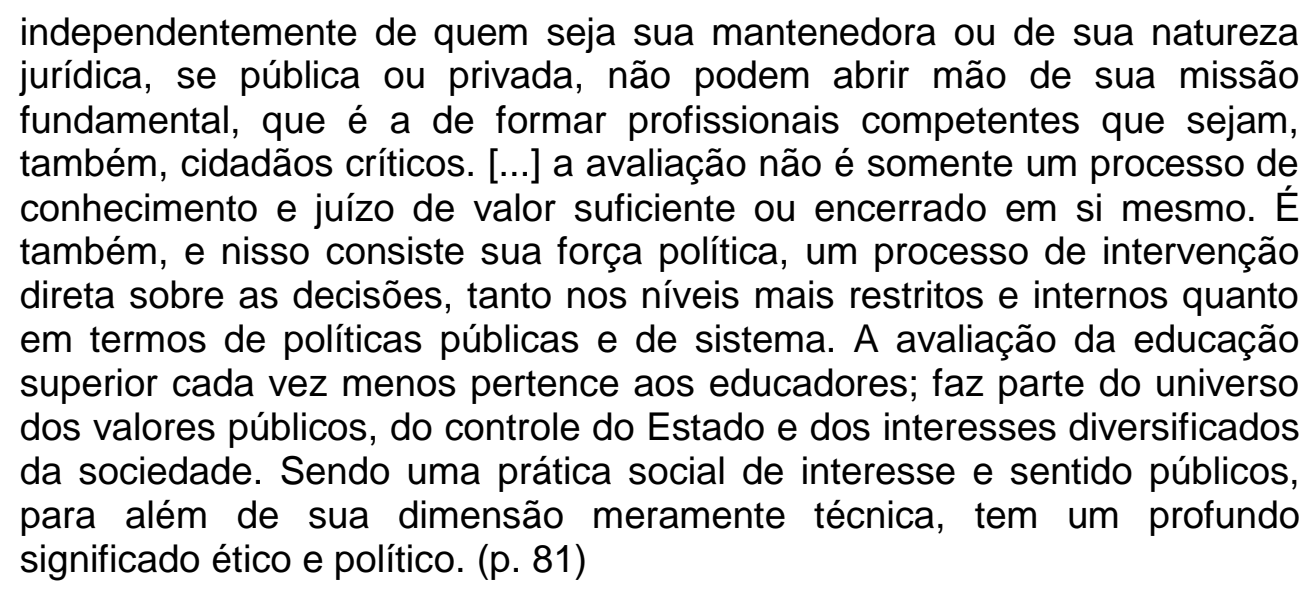

Criado pela lei n. 2.864, de 6 de junho de 1962, o Conselho Estadual de Educação da Paraíba - CEE/PB - é um órgão colegiado do sistema de ensino e tem como objetivo interpretar a legislação federal e estadual, adaptando-as ao sistema de ensino do Estado. Segundo Leitão (1987) o CEE/PB foi um dos primeiros conselhos estaduais a serem criados no país. Além de ter sido pioneiro em emitir uma resolução disciplinando a implantação dos conselhos municipais de educação.

Conforme Bordignon (2009), os conselhos de educação foram criados como órgãos técnicos de colaboração superior, com a função elementar de colaborar na formulação das políticas e diretrizes educacionais no interior dos sistemas. Essa atribuição estabelece os conselhos como órgãos normativos.

A legislação vigente do CEE/PB é a lei n. 7.653, de 6 de setembro de 2004, a qual estabelece as atribuições do CEE/PB, bem como dos seus conselheiros. No ano seguinte foi aprovado o Regimento Interno do CEE/PB, pela resolução n. 172, de 28 de julho de 2005. Por meio desta normativa foram exemplificadas a natureza e as finalidades do CEE/PB como órgão com atribuição normativa, deliberativa, propositiva e consultiva. 
No que alcança a UEPB, como autarquia do governo estadual e, portanto, submetida, para fins de avaliação institucional e de seus cursos de graduação ao CEE/PB, a resolução n. 020/2008 do CEE/PB dispõe sobre o recredenciamento da UEPB e dá outras providências. De acordo com a regulamentação, o prazo de validade do credenciamento institucional é de oito anos e o pedido deverá ser encaminhado pela universidade até seis meses antes de esgotar o prazo do recredenciamento anterior.

Já a resolução n. 086/2007 do CEE/PB disciplina o reconhecimento e a renovação de reconhecimento de cursos de nível superior. No cenário da UEPB, dos 53 cursos de graduação em funcionamento 29 passaram pelo processo de reconhecimento ou renovação do reconhecimento no ano de 2019. Entretanto, apenas oito tiveram seu relatório e análise concluídos. Cabe ressaltar que, conforme a referida resolução, caso aprovado, o reconhecimento terá validade de seis anos e, posteriormente, de acordo com o art. 3 e " $\S 1^{\circ}$, a renovação do reconhecimento deverá ser solicitada até 180 dias antes da extinção do prazo de validade do reconhecimento".

Neste trabalho debruçou-se sobre a análise do processo de avaliação dos cursos de graduação presencial na UEPB no ano de 2019, visando a identificar as práticas de avaliação da instituição. Adotou-se uma abordagem qualitativa, de caráter exploratório, com estratégia documental. Além disso adotamos a análise Swot como recurso na contribuição de identificação das forças, fraquezas, oportunidades e ameaças que impactaram de forma positiva e negativa na qualidade do processo avaliativo dos cursos de graduação presencial da UEPB.

\section{Avaliação de cursos de graduação presencial na UEPB}

O caminho da pesquisa foi a análise dos seis cursos de graduação presencial que tiveram o conceito valorativo quatro determinado segundo os relatórios da comissão avaliativa estabelecida pelo CEE/PB, na perspectiva da análise Swot, como instrumento que contribuiu na identificação das forças, fraquezas, oportunidades e ameaças que foram favoráveis a impactar positiva ou negativamente a qualidade da educação no contexto da UEPB.

A análise Swot corresponde "à identificação por parte da organização e, de forma integrada, dos principais aspectos que caracterizam a sua posição estratégica num determinado momento, tanto interna como externamente" (Silveira, 2001, p. 209). Dessa forma, a análise Swot é uma ferramenta de gestão

muito utilizada porque permite promover um confronto entre as variáveis externas e internas à organização, facilitando a geração de alternativas que possam orientar escolhas estratégicas e possíveis linhas de ação. Como é uma análise do ambiente, sua ênfase está no diagnóstico dos pontos fracos e fortes e das oportunidades e ameaças, para que seja definido o ambiente no qual a organização encontra-se inserida. O objetivo é conhecer o ambiente interno da organização - por intermédio da definição dos seus pontos fortes e fracos em relação aos concorrentes bem como identificar o ambiente externo a esta, que são as ameaças e as oportunidades. 
Assim, a análise Swot monitora, simultaneamente, os ambientes interno e externo e adota ações diferentes para cada situação, ressaltando que o ambiente interno pode ser controlado pelos dirigentes da organização - pois é o resultado de estratégias de atuação definidas pela própria instituição - ao contrário do ambiente externo, que foge totalmente ao controle da organização, sendo o seu monitoramento uma oportunidade de se evitar possíveis ameaças, agindo de forma preventiva, proativa, ágil e eficiente (Guerra; Cavalcanti, 2020).

Para Guerra e Ribeiro (2019), "a análise de Swot se constitui em um método de efetiva relevância na identificação das forças, fraquezas, oportunidades e ameaças em que as empresas se inserem" (p. 5). A matriz Swot, como referência de base para tomada de decisões, possibilita a formulação de políticas que serão aplicadas no processo de planejamento estratégico adotando procedimentos a fim de buscar sua subsistência e desenvolvimento institucional. Conforme Guerra; Souza (2020) a matriz Swot possibilita uma análise

panorâmica em quatro cenários, de modo a permitir a compreensão global da realidade em que a organização está inserida e, por conseguinte, amplia as informações que irão nortear a estratégia de planejamento mais adequada à situação concreta daquela instituição. (p. 410)

Utilizou-se a seguinte estratégia para a elaboração da matriz Swot no que se refere ao ambiente interno: primeiro foi feito um diagnóstico numa perspectiva de sintetizar a análise dos relatórios das comissões de verificação in loco, sendo classificada a avaliação em cada descritor/indicador. Desse modo identificou-se como Forças o somatório de indicadores avaliados em S (satisfatoriamente), e para a categoria Fraquezas foram considerados o somatório de indicadores avaliados $P$ (parcialmente) e $N$ (não). Não foram considerados o somatório de indicadores que, dentre os seis cursos avaliados, obtiveram empates numéricos, não se constituindo, sob o nosso ponto de vista, nem em Fraqueza, nem em Força; bem como quando o descritor não se aplica ao curso foi especificado como NSA, e, uma vez que se está analisando o ambiente interno dos cursos referenciados, os indicadores pontuados com empates numéricos ou NSA não puderam ser classificados como Oportunidades ou Ameaças, componentes estes relacionados ao ambiente externo.

Assim sendo, esquematizou-se as Forças e Fraquezas dos cursos com base nos dados dos quadros 7, 8 e 9 e optou-se por diagnosticar as Forças e as Fraquezas pelo instrumento utilizado pelo CEE/PB e por curso de graduação avaliado com relatório disponibilizado pelo CEE/PB à UEPB.

Para consecução do ambiente externo, o qual aponta as Oportunidades e Ameaças, foi empregado consoante o quadro 10 e o relatório das comissões de verificação in loco. Entretanto, diferente da estruturação aplicada para o ambiente interno, a metodologia utilizada baseou-se nas perspectivas positivas e negativas elencadas pelos avaliadores ao pesar a verificação e as considerações da comunidade acadêmica envolvida no processo. Diante disso, ao apontar fatores externos a IES, foi necessário contextualizar dados e documentos que melhor elucidassem os aspectos inerentes a interpretação das ameaças e oportunidades. 
Reafirmamos que o CEE/PB considerou como referência o instrumento de avaliação de cursos de graduação presencial e a distância do Sinaes, indicando uma adaptação uma redução que, em nosso entendimento, dificulta o apontamento detalhado da condição em que o curso se encontra, bem como da representatividade na pesquisa de quais aspectos positivos e negativos eles apresentam. Isto porque o instrumento do Inep apresenta cinco opções de enquadramento do curso segundo cada indicador/descritor, o que corresponde ao conceito e ao critério de análise de 1 a 5 , ou seja, favorecendo a ação dos avaliadores para que classifiquem de uma forma mais adequada a realidade identificada em cada curso.

Já o IACG do CEE/PB apresenta uma adaptação que se restringe a suprimir os conceitos e critérios de análise de 1 a 4 , considerando, exclusivamente, o item 5 para que os avaliadores utilizem como parâmetro. Isto significa, em nossa compreensão, limitar o horizonte de análise e enquadrar a perspectiva de avaliação a algo mais superficial, deixando à parte as especificidades que retratam cada critério no qual o curso pode ser categorizado. Ao considerar apenas o critério 5 , que é o parâmetro máximo que um curso pode alcançar naquele determinado indicador/descritor, o não atingimento e 0 apontamento que não contempla aquele aspecto, distorcem o objetivo da avaliação e deixam de contribuir de forma qualitativa na ação do curso em identificar sua condição atual para repensar suas práticas, ou seja, a existência dos indicadores e critérios de análise de 1 a 5 auxiliam em proporcionar o entendimento de onde o curso se encontra e até onde ele pode avançar.

A adaptação feita pelo CEE/PB do instrumento do Inep foi o recorte dos conceitos 1 , 2, 3 e 4 no item de critério de análise, considerando, exclusivamente, o conceito $5 \mathrm{em}$ todos os indicadores e nas três dimensões do instrumento.

\section{Diagnóstico dos relatórios de avaliação das comissões de verificação in loco}

Feita a contextualização do instrumento utilizado pela comissão de verificação in loco, elaboramos três quadros-síntese referentes às três dimensões do instrumento de avaliação e neles sintetizamos os relatórios elaborados pela comissão de cada um dos seis cursos presenciais de graduação objetos da pesquisa.

$\mathrm{O}$ quadro 1 apresenta a primeira dimensão: organização didático-pedagógica. $\mathrm{Na}$ síntese constam os 24 descritores que a compõem e a categorização com a qual cada um se relaciona. Cabe destacar que a dimensão mencionada está centrada em confrontar o que é estabelecido nas legislações, documentos institucionais, em especial o PPC, com a realidade explorada na avaliação in loco.

Num cenário de atribuição de peso - valor quantitativo - para as três dimensões que fazem parte do instrumento de avaliação, como meio de conferir um conceito de curso, para a referida dimensão foi empregado o peso 30, considerando um total de 100. 
Quadro 1 -

Dimensão 1: organização didático-pedagógica.

\begin{tabular}{|c|c|c|c|c|c|c|}
\hline Descritor & Mat VII ${ }^{3}$ & FísVII ${ }^{4}$ & $\mathrm{CoVII}^{5}$ & $\mathrm{Col}^{6}$ & $\mathrm{EdFI}^{7}$ & Fisiol $^{8}$ \\
\hline $\begin{array}{l}\text { 1.1 Políticas institucionais no âmbito } \\
\text { do curso }\end{array}$ & $\mathrm{P}^{9}$ & $\mathrm{P}$ & $\mathrm{S}^{10}$ & S & $\mathrm{S}$ & $\mathrm{P}$ \\
\hline 1.2 Objetivo do curso & $\mathrm{P}$ & $\mathrm{P}$ & S & S & S & S \\
\hline 1.3 Perfil profissional dos egressos & S & S & S & S & S & $\mathrm{S}$ \\
\hline 1.4 Estrutura curricular & $\mathrm{N}^{11}$ & $\mathrm{~N}$ & $P$ & $P$ & S & S \\
\hline 1.5 Conteúdos curriculares & S & S & $\mathrm{P}$ & $\mathrm{P}$ & S & S \\
\hline 1.6 Metodologia & $\mathrm{N}$ & $\mathrm{N}$ & $\mathrm{N}$ & $\mathrm{S}$ & $\mathrm{S}$ & $\mathrm{S}$ \\
\hline 1.7 Estágio curricular supervisionado & S & S & $\mathrm{N}$ & S & S & S \\
\hline $\begin{array}{l}\text { 1.8 Estágio curricular supervisionado } \\
\text { - relação com a rede de escolas da } \\
\text { educação básica }\end{array}$ & S & S & $\mathrm{NSA}^{12}$ & NSA & S & NSA \\
\hline $\begin{array}{l}1.9 \text { Estágio curricular supervisionado } \\
\text { - relação teoria e prática }\end{array}$ & S & $\mathrm{N}$ & NSA & S & S & S \\
\hline $\begin{array}{l}1.10 \text { Obrigatório para cursos cujas } \\
\text { DCN preveem atividades } \\
\text { complementares }\end{array}$ & $P$ & $P$ & $P$ & S & S & S \\
\hline $\begin{array}{l}1.11 \text { Trabalhos de conclusão de } \\
\text { curso }\end{array}$ & $P$ & $P$ & S & S & S & S \\
\hline 1.12 Apoio ao discente & S & S & $\mathrm{P}$ & $\mathrm{P}$ & S & S \\
\hline $\begin{array}{l}1.13 \text { Gestão do curso e os } \\
\text { processos de avaliação interna e } \\
\text { externa }\end{array}$ & S & S & $P$ & S & S & S \\
\hline 1.14 Atividades de tutoria & NSA & NSA & $\mathrm{NSA}$ & NSA & NSA & NSA \\
\hline $\begin{array}{l}1.15 \text { Conhecimentos, habilidades e } \\
\text { atitudes necessárias às atividades } \\
\text { de tutoria }\end{array}$ & NSA & NSA & NSA & NSA & NSA & NSA \\
\hline $\begin{array}{l}\text { 1.16 Tecnologias de Informação e } \\
\text { Comunicação no processo ensino- } \\
\text { aprendizagem }\end{array}$ & S & S & S & $P$ & S & $\mathrm{P}$ \\
\hline $\begin{array}{l}1.17 \text { Ambiente virtual de } \\
\text { aprendizagem }\end{array}$ & NSA & NSA & NSA & NSA & NSA & NSA \\
\hline 1.18 Material didático & NSA & NSA & NSA & NSA & NSA & NSA \\
\hline $\begin{array}{l}\text { 1.19 Procedimentos de } \\
\text { acompanhamento e de avaliação } \\
\text { dos processos de } \\
\text { ensino-aprendizagem }\end{array}$ & $P$ & S & S & S & S & $\mathrm{P}$ \\
\hline 1.20 Número de vagas & S & S & S & $S$ & $\mathrm{~S}$ & $S$ \\
\hline $\begin{array}{l}1.21 \text { Integração com as redes } \\
\text { públicas de ensino }\end{array}$ & S & S & NSA & NSA & S & NSA \\
\hline $\begin{array}{l}1.22 \text { Integração do curso com o } \\
\text { sistema local e regional de saúde }\end{array}$ & NSA & NSA & NSA & NSA & NSA & S \\
\hline
\end{tabular}

${ }^{3}$ Matemática, licenciatura, campus VII.

${ }^{4}$ Física, licenciatura, campus VII.

${ }^{5}$ Computação, bacharelado, campus VII.

${ }^{6}$ Computação, bacharelado, campus I.

7 Educação Física, bacharelado, campus I.

${ }^{8}$ Fisioterapia, bacharelado, campus I.

${ }^{9}$ Quando o curso atinge parcialmente o que é descrito no conceito 5 .

${ }_{10}$ Quando o curso atinge satisfatoriamente o que é descrito no conceito 5.

${ }_{11}$ Quando o curso não atinge o que é descrito no conceito 5.

12 Quando o descritor não se aplica ao curso.

Regae: Rev. Gest. Aval. Educ. Santa Maria

v. 10

n. 19

e55373, p. 1-17

2021 


\begin{tabular}{|l|c|c|c|c|c|c|}
\hline $\begin{array}{l}1.23 \text { Atividades práticas de ensino } \\
\text { para áreas da saúde }\end{array}$ & NSA & NSA & NSA & NSA & NSA & S \\
\hline $\begin{array}{l}1.24 \text { Atividades práticas de ensino } \\
\text { para licenciaturas }\end{array}$ & S & P & NSA & NSA & NSA & NSA \\
\hline
\end{tabular}

Fonte: autores (2020).

Já a segunda dimensão - corpo docente e tutorial - apresenta dezesseis descritores. Dentre as três dimensões do instrumento de avaliação é a que apresenta maior peso, 40, em comparação com as demais. Nesse sentido infere-se a importância de um conjunto de docentes qualificados, com vínculo efetivo e com experiência profissional e na docência, para o êxito do curso na avaliação in loco.

Quadro 2 -

Dimensão 2: corpo docente e tutorial.

\begin{tabular}{|c|c|c|c|c|c|c|}
\hline Descritor & Mat VII & FísVII & CoVII & Col & EdFI & Fisiol \\
\hline $\begin{array}{l}\text { 2.1 Núcleo docente estruturante - } \\
\text { NDE }\end{array}$ & $\mathrm{P}$ & S & S & S & S & S \\
\hline 2.2 Equipe multidisciplinar & NSA & NSA & NSA & NSA & NSA & NSA \\
\hline 2.3 Atuação do coordenador & $\mathrm{S}$ & $\mathrm{S}$ & $\mathrm{S}$ & $\mathrm{S}$ & $\mathrm{S}$ & $\mathrm{S}$ \\
\hline $\begin{array}{l}\text { 2.4 Regime de Trabalho do } \\
\text { Coordenador }\end{array}$ & S & S & S & S & S & S \\
\hline 2.5 Corpo docente: titulação & $P$ & $P$ & S & S & S & $\mathrm{P}$ \\
\hline $\begin{array}{l}\text { 2.6 Regime de trabalho do corpo } \\
\text { docente do curso }\end{array}$ & $P$ & $\mathrm{~S}$ & $P$ & $\mathrm{~S}$ & $\mathrm{~S}$ & $\mathrm{~S}$ \\
\hline $\begin{array}{l}\text { 2.7 Experiência profissional do } \\
\text { docente }\end{array}$ & S & S & $P$ & $S$ & S & $P$ \\
\hline $\begin{array}{l}\text { 2.8 Experiência no exercício da } \\
\text { docência na educação básica }\end{array}$ & $\bar{N}$ & $\bar{N}$ & NSA & NSA & NSA & NSA \\
\hline $\begin{array}{l}\text { 2.9 Experiência no exercício da } \\
\text { docência superior }\end{array}$ & S & S & S & S & S & $P$ \\
\hline $\begin{array}{l}\text { 2.10 Experiência no exercício da } \\
\text { docência na educação a distância }\end{array}$ & NSA & NSA & NSA & NSA & NSA & NSA \\
\hline $\begin{array}{l}2.11 \text { Experiência no exercício da } \\
\text { tutoria na educação a distância }\end{array}$ & NSA & NSA & NSA & NSA & NSA & NSA \\
\hline $\begin{array}{l}\text { 2.12 Atuação do colegiado de curso } \\
\text { ou equivalente }\end{array}$ & $P$ & $P$ & S & S & S & S \\
\hline $\begin{array}{l}\text { 2.13 Titulação e formação do corpo } \\
\text { de tutores do curso }\end{array}$ & NSA & $\overline{N S A}$ & NSA & NSA & NSA & NSA \\
\hline $\begin{array}{l}\text { 2.14 Experiência do corpo de tutores } \\
\text { em educação a distância }\end{array}$ & NSA & NSA & NSA & NSA & NSA & NSA \\
\hline $\begin{array}{l}2.15 \text { Interação entre tutores } \\
\text { (presenciais - quando for o caso - e a } \\
\text { distância), docentes e coordenadores } \\
\text { de curso a distância }\end{array}$ & NSA & NSA & NSA & NSA & NSA & NSA \\
\hline $\begin{array}{l}\text { 2.16 Produção científica, cultural, } \\
\text { artística ou tecnológica }\end{array}$ & $S$ & $S$ & $P$ & $S$ & $S$ & $S$ \\
\hline
\end{tabular}

Fonte: autores (2020). 
A terceira dimensão - infraestrutura - encerra a síntese feita de acordo com o instrumento de avaliação. Ressalta-se que, conforme a distribuição de pesos nas dimensões para obtenção da média equivalente ao conceito de curso, a terceira empreende a fração de 30.

Quadro 3 -

Dimensão 3: infraestrutura.

\begin{tabular}{|c|c|c|c|c|c|c|}
\hline Descritor & Mat VII & FísVII & CoVII & Col & EdFI & Fisiol \\
\hline $\begin{array}{l}\text { 3.1 Espaço de trabalho para docentes } \\
\text { em tempo integral }\end{array}$ & S & S & $\mathrm{N}$ & S & S & S \\
\hline $\begin{array}{l}\text { 3.2 Espaço de trabalho para o } \\
\text { coordenador }\end{array}$ & $P$ & $P$ & $P$ & S & $S$ & $S$ \\
\hline 3.3 Sala coletiva de professores & $P$ & $P$ & $P$ & S & S & S \\
\hline 3.4 Salas de aula & $P$ & $P$ & S & $\mathrm{P}$ & $\mathrm{P}$ & S \\
\hline $\begin{array}{l}\text { 3.5 Acesso de alunos aos } \\
\text { equipamentos de informática }\end{array}$ & P & P & S & P & $\mathrm{P}$ & S \\
\hline $\begin{array}{l}\text { 3.6 Bibliografia básica por unidade } \\
\text { curricular (UC) }\end{array}$ & P & P & $S$ & P & $P$ & $S$ \\
\hline $\begin{array}{l}\text { 3.7 Bibliografia Complementar por } \\
\text { Unidade Curricular (UC) }\end{array}$ & $P$ & $P$ & $\mathrm{~N}$ & P & $P$ & S \\
\hline $\begin{array}{l}\text { 3.8 Laboratórios didáticos de } \\
\text { formação básica }\end{array}$ & $\mathrm{P}$ & $P$ & NSA & S & $P$ & S \\
\hline $\begin{array}{l}\text { 3.9 Laboratórios didáticos de } \\
\text { formação específica }\end{array}$ & S & S & NSA & $S$ & $P$ & $S$ \\
\hline $\begin{array}{l}\text { 3.10 Laboratórios de ensino para a } \\
\text { área de saúde }\end{array}$ & NSA & NSA & NSA & NSA & NSA & S \\
\hline 3.11 Laboratórios de habilidades & NSA & $S$ & NSA & NSA & NSA & $S$ \\
\hline $\begin{array}{l}\text { 3.12 Unidades hospitalares e } \\
\text { complexo assistencial conveniados }\end{array}$ & NSA & NSA & NSA & NSA & NSA & NSA \\
\hline 3.13 Biotérios & NSA & S & NSA & NSA & NSA & NSA \\
\hline $\begin{array}{l}\text { 3.14 Processo de controle de } \\
\text { produção ou distribuição de material } \\
\text { didático (logística) }\end{array}$ & NSA & NSA & NSA & NSA & NSA & NSA \\
\hline $\begin{array}{l}\text { 3.15 Núcleo de práticas jurídicas: } \\
\text { atividades básicas e arbitragem, } \\
\text { negociação, conciliação, mediação e } \\
\text { atividades jurídicas reais }\end{array}$ & NSA & NSA & NSA & NSA & NSA & NSA \\
\hline 3.16 Comitê de ética em pesquisa & $\mathrm{S}$ & $\mathrm{S}$ & $\mathrm{S}$ & $\mathrm{S}$ & $\mathrm{S}$ & $\mathrm{S}$ \\
\hline $\begin{array}{l}3.17 \text { Comitê de ética na utilização de } \\
\text { animais (CEUA) }\end{array}$ & NSA & NSA & NSA & NSA & NSA & NSA \\
\hline $\begin{array}{l}3.18 \text { Ambientes profissionais } \\
\text { vinculados ao curso }\end{array}$ & NSA & NSA & NSA & NSA & NSA & NSA \\
\hline
\end{tabular}

Fonte: autores (2020).

Conforme apontado nas três dimensões dispostas nos quadros acima e classificados de acordo com a categoria indicada segundo os relatórios elaborados pelas comissões de verificação in loco dos seis cursos de graduação presencial, procedemos então à elaboração da análise Swot, tomando como referencial os quadros citados para extrair as forças e fraquezas presentes no processo avaliativo. 


\section{Ambiente interno: forças e fraquezas}

Foram considerados os aspectos positivos e negativos presentes nos relatórios de avaliação dos seis cursos presenciais de graduação avaliados, de forma que expresse as qualidades e fragilidades apresentadas pelos cursos e, principalmente, sirva como mais um instrumento para refletir as ações em busca do aprimoramento das atividades dos cursos e da IES.

Organizado consoante as três dimensões apresentadas nos quadros-síntese, ressalta-se que o objetivo de uma análise de ambiente interno com base nos relatórios é pensar o que pode ser melhorado no âmbito do curso e apontar o que existe em excelência. Entretanto, compreende-se que algumas ações fogem da alçada dos cursos e englobam políticas institucionais e de gestão universitária.

Para ser considerado como força um descritor, de acordo com o bloco de seis cursos, era necessário que atingíssemos três ou mais relatórios de avaliação de cursos classificado como satisfatório (S). Já para indicar as fraquezas, pela adaptação feita ao IACG do Inep e a impossibilidade de classificar os critérios de análise de 1 a 5 , levamos em conta a junção dos conceitos parcialmente $(P)$ e não $(N)$, em somatórias que ultrapassassem os classificados como satisfatório (S). É fundamental, também, mencionar os recortes considerados para delimitação das forças e fraquezas, quais sejam: para os casos de empates numéricos, ou seja, itens que tiverem três considerados como força e três considerados como fraqueza, foram retirados, pois não se poderia elencar em qual perspectiva figuraria. Além disso, os descritores que tinham ao menos um conceito não se aplica (NSA) foram também desconsiderados, pois não possibilitavam uma análise de um todo.

Diante dos aspectos considerados apresentamos, de acordo com a matriz Swot, o ambiente interno, que aponta as forças e fraquezas identificadas de acordo com o relatório de avaliação da comissão de verificação in loco dos seis cursos presenciais objetos da pesquisa. São três quadros das dimensões dispostas no IACG do CEE/PB. O quadro 4, referente à dimensão de organização didático-pedagógica, evidenciou que, segundo os relatórios concebidos e a análise Swot, dez descritores são considerados como força e um descritor, como fraqueza.

Quadro 4 -

Análise Swot dimensão 1: organização didático-pedagógica.

\begin{tabular}{|l|l|}
\hline \multicolumn{2}{|c|}{ Dimensão 1: organização didático-pedagógica } \\
\hline & Descritor 1.2 Objetivo do curso \\
& Descritor 1.3 Perfil profissional dos egressos \\
& Descritor 1.5 Conteúdos curriculares \\
& Descritor 1.7 Estágio curricular supervisionado \\
& Descritor 1.11 Trabalhos de conclusão de curso \\
Foscritor 1.12 Apoio ao discente & Descritor 1.13 Gestão do curso e os processos de avaliação interna e \\
& externa \\
& Descritor 1.16 Tecnologias de informação e comunicação no processo \\
& ensino-aprendizagem \\
& Descritor 1.19 Procedimentos de acompanhamento e de avaliação dos \\
processos de ensino-aprendizagem & Descritor 1.20 Número de vagas \\
\hline Fraquezas & Descritor 1.4 Estrutura curricular \\
\hline
\end{tabular}

Fonte: autores (2020). 
Na primeira dimensão - organização didático-pedagógica - dos 24 descritores do IACG do CEE/PB foram suprimidos treze, sendo dez por não se aplicarem e três por situação de empate numérico no conjunto dos seis cursos. Assim sendo, restaram 11 descritores, dos quais dez foram classificados como força. Apresentamos a seguir algumas considerações levantadas de acordo com os relatórios da comissão de verificação in loco.

No descritor 1.2, referente ao objetivo do curso, depreende-se que os dados estão elencados de forma clara, apresentando coerência com o perfil do profissional que se pretende graduar. Sugerindo-se incluir o componente curricular de estágio supervisionado como obrigatório em todos os cursos, pois fortaleceria a sintonia com as necessidades regionais e nacionais e a atuação profissional crítica e ética.

Outro descritor categorizado como força é o 1.3, sobre o perfil profissional do egresso, evidenciando que os cursos avaliados atendem às demandas dos PCCs e as DCNs satisfatoriamente. Recomendando-se que alguns componentes curriculares classificados como eletivos deveriam migrar para o grupo de obrigatórios como meio de contribuir melhor com o perfil do egresso.

O descritor 1.5 - conteúdos curriculares - está avaliado positivamente, pois os cursos promovem o efetivo desenvolvimento do perfil profissional do egresso e as temáticas de inclusão. Entretanto, sugere que alguns cursos atentem para a necessária atualização das ementas e das referências de alguns componentes curriculares. Em alguns casos cabe incluir componentes livres ou em temáticas transversais a exemplo da educação ambiental, educação em direitos humanos, educação das relações étnico-raciais, o ensino da história e cultura afro-brasileira, africana e indígena.

O descritor 1.7 aborda a perspectiva do estágio curricular supervisionado e observou-se que apresenta consonância com a legislação de estágios e a carga horária está correta e sendo desenvolvida ao logo dos cursos. Reiterasse, em alguns casos, a fundamental relevância de incluir o estágio curricular supervisionado no quadro de disciplinas obrigatórias.

Acerca do trabalho de conclusão de cursos, que corresponde ao descritor 1.11, estão previstos nos PPCs dos cursos; atende às exigências do curso, devendo ter um enfoque maior no ensino da licenciatura para os cursos dessa característica; rever a divergência nas cargas horárias de TCC constante no regimento da graduação com as dispostas nos PPCs; criação de resolução própria de TCC para cada curso;

Em relação ao descritor 1.12 - apoio ao discente - constatou-se grande oferta de projetos de pesquisa, restaurante universitário e bolsas em programas de assistência estudantil, boa atuação no apoio ao ensino e na relação docente-discente bem referenciada, assim como a integração do curso com o sistema de saúde local e regional/SUS. Segundo os discentes, apesar da existência dos programas, dos projetos e da assistência, carece de melhor divulgação institucional.

No tocante ao descritor 1.13 - Gestão do curso e os processos de avaliação interna e externa -, conforme os relatórios, a avaliação feita pela CPA e a autoavaliação feita pelo NDE dos cursos são satisfatórias. A CPA, de um modo geral, necessita de melhoramentos nos procedimentos informatizados para subsidiar, em tempo hábil, as ações da gestão da instituição e dos cursos. 
O descritor 1.16, acerca das tecnologias de informação e comunicação no processo ensino-aprendizagem, identificou que parte dos docentes utilizam esses recursos, entretanto, carecem de maior adesão. Além disso, institucionalmente, no âmbito dos cursos, precisa haver ampliação das capacitações para uso das TICs e metodologias ativas.

Sobre o descritor 1.19 e os procedimentos de acompanhamento e de avaliação dos processos de ensino-aprendizagem, esses atendem ao que prescreve os PPCs mas, em alguns casos, falta clareza na explicação. O funcionamento do sistema de controle acadêmico é bom, entretanto, faz-se necessário definir uma data limite para os docentes implementarem as notas dos discentes.

A respeito do descritor 1.20, que analisa o número de vagas, compreende-se que é adequado aos cursos. Indicando apenas atenção para as condições estruturais na decisão do oferecimento do número de vagas.

No que se refere a fraquezas, segundo os relatórios das comissões de avaliação in loco, apenas o descritor 1.4 - estrutura curricular - foi apontado como algo que precisa melhorar. São recomendados aspectos para uma melhor organização, adequação e reestruturação do PPC, em alguns casos, atentar para as diretrizes curriculares nacionais e suas atualizações, visto que o PPC avaliado foi construído em 2016 e até então, em alguns cursos, houve modificações nas DCN's. Outra observação decorre do componente curricular Língua Brasileira de Sinais, para que constem nos PPC's como, pelo menos, eletivo, para os bacharelados, visto que alguns não oferecem a disciplina em sua estrutura curricular. Aponta-se também que em alguns casos a estrutura curricular não apresenta os instrumentos de articulações entre os saberes e sua transposição às exigências do PPC, bem como explicitar nas ementas das disciplinas a exigência de atividades práticas, descritas e executadas pelos atuais docentes.

Apresentamos agora o quadro 5 , concernente à dimensão de corpo docente e tutorial. Conforme os relatórios elaborados e a análise Swot oito descritores são considerados como força e nenhum como fraqueza.

Quadro 5 -

Análise Swot dimensão 2: corpo docente e tutorial.

\begin{tabular}{|l|l|}
\hline \multicolumn{1}{|c|}{ Dimensão 2: corpo docente e tutorial } \\
\hline \multirow{5}{*}{ Forças } & Descritor 2.1 Núcleo docente estruturante \\
& Descritor 2.3 Atuação do coordenador \\
& Descritor 2.4 Regime de trabalho do coordenador \\
& Descritor 2.6 Regime de trabalho do corpo docente do curso \\
& Descritor 2.7 Experiência profissional do docente \\
& Descritor 2.9 Experiência no exercício da docência superior \\
& Descritor 2.12 Atuação do colegiado de curso ou equivalente \\
& Descritor 2.16 Produção científica, cultural, artística ou tecnológica \\
\hline Fraquezas & Não houve \\
\hline
\end{tabular}

Fonte: autores (2020). 
No quadro 5 apresentamos a perspectiva da comissão quanto à segunda dimensão: corpo docente e tutorial). Dos 16 descritores do IACG do CEE/PB foram suprimidos sete, sendo seis por não se aplicarem (NSA) e um por situação de empate numérico no conjunto dos seis cursos. Portanto, restaram oito descritores e, segundo os parâmetros estabelecidos, todos foram classificados como força, são eles.

O descritor 2.1 aborda o desempenho do Núcleo Docente Estruturante - NDE - e, de acordo com o constatado, apresenta uma atuação muito boa, com acompanhamento, a consolidação e a avaliação do PCC, além de perspectivas de inovação. Ademais, possui cada um, no mínimo, cinco docentes, com maior parte detentor de titulação stricto sensu. Alerta-se para o número reduzido de professores efetivos que, em alguns contextos, pode dificultar a qualidade dos trabalhos.

Outro descritor indicado como força é o 2.3, acerca da atuação do coordenador. Segundo os relatórios esse promove ação integradora entre NDE, chefia de departamento, colegiado do curso e coordenação do curso, além de participar e estar presente nas atividades dos cursos.

Sobre o descritor 2.4, que trata do regime de trabalho do coordenador, em síntese, atende o prescrito, sendo integral e com dedicação exclusiva. No aspecto de regime de trabalho do corpo docente do curso que corresponde ao descritor 2.6, percebeu-se que a maioria ocupa cargos de dedicação exclusiva, o que permite 0 atendimento integral da demanda existente. Contudo, possui um quadro de professores substitutos elevado.

O descritor 2.7 versa sobre a experiência profissional do docente que, em sua maioria, possui experiência profissional. Parte deles possui experiência no mercado de trabalho, trazendo contribuições para a sala de aula. Porém, boa parte dos docentes, dos cursos de licenciatura, não possui experiências na formação do ensino básico.

Mais uma força identificada é o descritor 2.9, referente à experiência no exercício da docência superior. Identificou-se que o corpo docente possui experiência suficiente para promover as ações e empreende experiência acadêmica, promovendo ações que otimizam o processo de ensino-aprendizagem. Sugere-se reconsiderar em editais casos de docentes apenas com nível de graduação para compor o quadro de professores.

No que corresponde ao descritor 2.12, que retrata a atuação do colegiado de curso ou equivalente, mostrou-se que os colegiados se reúnem de acordo com as demandas dos discentes, possuem sua representatividade, entretanto, não fazem avaliação periódica.

Concluindo as forças anunciadas na segunda dimensão do IACG do CEE/PB, o descritor 2.16 dedica-se a indagar quanto à produção científica, cultural, artística ou tecnológica. Nesse sentido, segundo os relatórios elaborados pelas comissões de verificação in loco, os cursos possuem parcerias com a Pró-Reitoria de Cultura, que dispõe do centro artístico cultural e diversas atividades de teatro, música, dança e artes visuais; também, que os docentes apresentam produção cientifica anual. Em alguns contextos metade do corpo docente atende ao critério de possuir, no mínimo, nove produções nos últimos três anos.

A dimensão de infraestrutura, consoante os relatórios realizados e a análise Swot, apresentou dois descritores avaliados como força e quatro como fraquezas. 
Quadro 6 -

Análise Swot dimensão 3: infraestrutura.

Dimensão 3: infraestrutura

\begin{tabular}{|c|l|}
\hline \multicolumn{2}{|c|}{ Dimensão 3: infraestrutura } \\
\hline Forças & Descritor 3.1 Espaço de trabalho para docentes em tempo integral \\
& Descritor 3.16 Comitê de Ética em Pesquisa \\
\hline \multirow{3}{*}{ Fraquezas } & Descritor 3.4 Salas de aula \\
& Descritor 3.5 Acesso de alunos aos equipamentos de informática \\
& Descritor 3.6 Bibliografia básica por unidade curricular \\
& Descritor 3.7 Bibliografia complementar por unidade curricular \\
\hline
\end{tabular}

Fonte: autores (2020).

$\mathrm{Na}$ terceira dimensão - infraestrutura, dos dezoito descritores do IACG do CEE/PB foram desconsiderados dez, sendo oito por não se aplicarem (NSA) e dois por situação de empate numérico no agrupamento dos seis cursos.

Considerado como força o descritor 3.1 questiona o espaço de trabalho para docentes em tempo integral. De acordo com a compreensão prescrita nos relatórios elaborados pelas comissões de verificação in loco, compreende-se que o espaço é suficiente, entretanto, a sala é coletiva e não individual.

Sobre o descritor 3.16, referente ao Comitê de Ética em Pesquisa depreende-se que o comitê é suficiente para o funcionamento da universidade.

No que se refere às fraquezas sinalizadas de acordo com a análise do ambiente interno da matriz Swot, percebe-se que a dimensão de infraestrutura é a que figura com mais aspectos negativos. No entanto, os apontamentos a esse respeito foram sintetizados por parte das comissões de verificação in loco.

No descritor 3.4, que afere aspectos referentes a salas de sula, os relatórios denotam um quantitativo insuficiente de salas de aula, a falta acessibilidade arquitetônica e precária estrutura física.

Em relação ao descritor 3.5 e ao acesso de alunos aos equipamentos de informática investigou-se que, ocasionalmente, faltam máquinas para que os discentes possam trabalhar no laboratório. Em outros momentos é insuficiente para atender aos programas.

$\mathrm{Na}$ perspectiva da bibliografia básica por unidade curricular, levantada pelo descritor 3.6, aponta-se a necessidade de uma ampliação. Já o descritor 3.7, sobre bibliografia complementar por unidade curricular, alerta que é necessário uma maior inserção, seja para componentes curriculares obrigatórios, seja para componentes curriculares eletivos.

Conforme apontado nos quadros 4, 5 e 6, referentes ao ambiente interno - forças e fraquezas -, podemos perceber que o quantitativo de forças foi significativamente maior. Entretanto, na terceira dimensão - infraestrutura -, esse indicador se inverteu apontando fragilidades relevantes.

Particularidades de cursos e áreas essências também foram mencionadas, como a melhora da quadra poliesportiva para o curso de Educação Física, a construção de piscina aquecida para a necessária utilização dos discentes do curso de Fisioterapia desenvolverem atividades práticas.

Outro item presente na avaliação negativa da infraestrutura foram as bibliotecas presencial e virtual, com apontamentos para melhora nos acervos para dar suporte aos componentes curriculares, inclusive, atentando para a insatisfatória oferta de referências complementares para alguns cursos de graduação. 
A falta de segurança é um ponto comum encontrado nas exposições dos relatórios de avaliação da comissão de verificação in loco, apontando, inclusive, uma revisão nos horários que os cursos integrais e noturnos são ofertados na instituição. Questões consoantes e elencadas pelos avaliadores como de infraestrutura foram a ampliação da assistência estudantil em seus vários aspectos e a realização de concurso público para contratação de professores efetivos como forma de qualificar o corpo docente da UEPB, visto que alguns cursos apresentam um quantitativo elevado de professores substitutos.

\section{Ambiente externo: ameaças e oportunidades}

O ambiente externo é considerado algo que foge dos limites da instituição mas que, de alguma forma, exerce influência sobre ela. Para Manager (2009) evitar as ameaças externas nem sempre é possível, porém, pode-se fazer um planejamento de contingência para enfrentá-las, diminuindo seus efeitos. Além disso, a devida atualização, planejamento e acompanhamento podem reagir positivamente e evitar grandes surpresas no âmbito das influências externas.

De acordo com o explorado nos relatórios de verificação in loco observamos a presença de quatro fatores que podem ser considerados como oportunidades para a instituição que, apesar de não possuir gerência acerca deles, pode favorecer-se por meio de suas ações e planejamento.

Quadro 7 -

Análise Swot dimensão 4: ambiente externo.

\begin{tabular}{|c|c|}
\hline \multicolumn{2}{|c|}{ Ambiente externo } \\
\hline Oportunidades & Ameaças \\
\hline Oferta escassa de cursos presenciais & Autonomia financeira não atendida \\
\hline $\begin{array}{l}\text { Convênios e projetos com agências de } \\
\text { fomento }\end{array}$ & Não realização de concurso público \\
\hline $\begin{array}{l}\text { Descentralização e regionalização para } 0 \\
\text { desenvolvimento do Estado }\end{array}$ & Descumprimento do PCCR \\
\hline Programas de apoio e assistência estudantil & Falta de acessibilidade arquitetônica \\
\hline
\end{tabular}

Fonte: autores (2020).

\section{Considerações finais}

Pela utilização da matriz Swot constatou-se que os cursos obtiveram bom desempenho quanto à primeira dimensão: organização didático pedagógica, com destaque para ação efetiva na atuação profissional crítica e ética e no perfil do egresso e com sugestões de melhorar a organização, adequação e reestruturação dos projetos pedagógicos de cursos em conformidade com as diretrizes curriculares nacionais e legislação vigente. Em relação à segunda dimensão - corpo docente e tutorial - a avaliação também mostrou um resultado satisfatório, denotando efetiva participação colaborativa do NDE, da coordenação dos cursos e dos departamentos e, enfatizando a circunstância de ter poucos professores efetivos nos quadros dos cursos avaliados.

Entretanto a terceira dimensão - infraestrutura - mostrou-se ser uma fraqueza apresentada pelos cursos e pela UEPB. $O$ aspecto que recebe maior visibilidade é a falta de acessibilidade arquitetônica. 
Conforme problematizado sugerimos que o CEE/PB adote, de forma integral, o instrumento de avaliação de cursos de graduação presencial e a distância do Sinaes como forma de melhor identificar as particularidades de cada curso e instituição avaliada, do mesmo modo que melhor subsidiará o trabalho da comissão de verificação in loco.

Propomos aos cursos de graduação uma revisão dos PPCs, atentando aos aspectos legais atualizados, as DCNs, ao regimento da graduação da instituição e à construção de uma cultura avaliativa no âmbito dos cursos.

Por fim, que a gestão administrativa da UEPB esteja vigilante quanto à atualização dos dados da IES no e-MEC; fomente e fiscalize o trabalho incipiente da CPA; elimine as inúmeras barreiras de acessibilidade existentes, assim como estabeleça melhores condições de infraestrutura e, mediante o restabelecimento da ordem financeira, aja para diminuição do quadro de docentes substitutos e o cumprimento do PCCR das categorias de docentes e técnico administrativos.

\section{Referências}

BORDIGNON, Genuíno. Gestão da educação no município: sistema, conselho e plano. São Paulo: Instituto Paulo Freire, 2009.

CAVALCANTI, Lourdes. Maria. Rodrigues; GUERRA, Maria das Graças. Gonçalves. Vieira. Diagnóstico Institucional da Universidade Federal da Paraíba a partir da Análise SWOT. Meta: Avaliação, Rio de Janeiro, v. 11, n. 33, 2019, p. 694-718.

DIAS SOBRINHO, José. Qualidade, avaliação: do SINAES a índices. Avaliação: Revista da Avaliação da Educação Superior, Campinas, v. 13, n. 3, 2008, p. 817-825.

FREITAS, Luiz Carlos de et.al. Avaliação educacional: caminhando pela contramão. Petrópolis: Vozes, 2011.

GUERRA, Maria das Graças Gonçalves Vieira; CAVALCANTI, Lourdes Maria Rodrigues. Uso da análise Swot e do ciclo PDCA para avaliação de cursos de graduação a partir do IACG 2017 (Sinaes). Curitiba: Appris, 2020.

GUERRA, Maria das Graças Gonçalves Vieira; RIBEIRO, Wagner Leite. Avaliação de cursos a partir do SINAES: uma análise para melhoria da qualidade na Universidade Federal da Paraíba. Revista Educação em Questão, Natal, v. 57, n. 53, 2019, p. 1-24.

GUERRA, Maria das Graças Gonçalves Vieira; SOUZA, Saulo Rodrigo Alves de. Avaliação da educação superior no Brasil. Regae - Revista de Gestão e Avaliação Educacional. Santa Maria, v. 9, n. 18, 2020, p. 1-18.

HAAS, Celia Maria. Educação superior no Brasil e os condicionamentos às políticas nacionais: impactos da regulação transnacional na gestão universitária. Laplage em Revista (Sorocaba), v.3, n.3, 2017, p.115-132.

INEP. Instrumento de avaliação de cursos de graduação - presencial e a distância: reconhecimento e renovação de reconhecimento. Brasília: Inep, 2017.

LEITÃO, Deusdedit de Vasconcelos. O ensino público na Paraíba: síntese histórica da Secretaria de Educação. João Pessoa: Governo do Estado, 1987.

NUNES, Enedina et al. Planejamento e avaliação institucional: um indicador do instrumento de avaliação do Sinaes. Avaliação (Campinas), Sorocaba, v. 22, n. 2, 2017, p. 373-384. 
PARAÍBA. Conselho Estadual de Educação: resoluções do ano de 2019. Disponível em https://cee.pb.gov.br/resolucoes/lista-de-resolucoes/2019/. Acesso em 5 abr. 2020.

SANTOS, Sérgio Machado. Análise comparativa dos processos europeus para a avaliação e certificação de sistemas internos de garantia da qualidade. Lisboa: A3ES, 2011.

SOUZA, Saulo Rodrigo Alves de; GUERRA, Maria das Graças Gonçalves Vieira. Autoavaliação institucional da Universidade Federal da Paraíba: diagnóstico a partir da Comissão Própria de Avaliação. Revista Diálogo Educacional, v. 20, n. 64, 2020, p. 405433.

VERHINE, Robert Evan. Avaliação e regulação da educação superior: uma análise a partir dos primeiros 10 anos do SINAES. Avaliação (Campinas), Sorocaba, v. 20, n. 3, 2015, p. 603-619.

VIEIRA, Sofia Lerche; NOGUEIRA, Jaana Flávia Fernandes. Políticas de avaliação e regulação da educação superior no Brasil. Revista Lusófona de Educação, Lisboa. n. 46, 2019, p. 11-24.

Bruno Henrique Oliveira Timbó é pedagogo na Universidade Estadual da Paraíba.

Orcid: https://orcid.org/0000-0002-1781-2879

Endereço: Rua Baraúnas, 351 - 58429-500 - Campina Grande - PB - Brasil.

E-mail: brunohenrique083@hotmail.com

Maria das Graças Gonçalves Vieira Guerra é professora na Universidade Federal da Paraíba.

Orcid: https://orcid.org/0000-0002-6943-0338

Endereço: Campus I - DHP-CE - 58051-900 - Campina Grande - PB - Brasil.

E-mail: gracinhavieira@yahoo.com.br.

Recebido em 25 de setembro de 2020.

Aceito em 2 de dezembro de 2020. 